\title{
Professionalism and Ethics in Financial Planning
}

\author{
June Smith, Anona Armstrong and Ronald Francis \\ Victoria University, Australia
}

\begin{abstract}
The purpose of this paper is to describe the analytical framework and methodology of a proposed study of the ethical reasoning of financial planners and the cognitive frameworks used to make ethical decisions in the provision of financial planning advice. The framework will draw on previous studies of individual characteristics such as ethical reasoning and the values and ethical development of a financial planner and consider the influence of situational and contextual factors such as organisational ethical climate and culture and the formal and informal control systems within an organisation. This is a significant study because the relationships financial planners have with their clients and the ethical framework that underpins them are pivotal to the ability of the financial planner to provide professional and effective independent advice.
\end{abstract}

\section{Keywords}

Ethics, professionalism, financial planning.

\section{Introduction}

Recent public debate suggests that financial planning is becoming increasing relevant to the achievement of the political and social objectives of Australians and their governments, including provision for retirement age and choice of superannuation fund (Weekes \& Hoyle 2004; Wilson 2004). There is an ever increasing and commensurate need to obtain expert financial planning advice to ensure a financially sustainable lifestyle and to provide for retirement years (Peel 2004; Gallop 2003).

There is therefore a greater focus on how that financial advice is delivered and on the regulatory and professional regimes that govern it (Smith, J. 2003; Powell 2003). This is illustrative of an international phenomenon being played out in a myriad of countries including the United States (Wagner 2004), Hong Kong (Gallop 2003) and the United Kingdom (Powell 2003).

Like other occupations such as architects (Matteson, 2002) and psychologists (Waring et al. 2003) financial planning seems to be becoming more professionalised and participants are moving towards new and important considerations of what it means, in an ethical sense, to be a financial planner (Wagner 2004; Walker 2003).

Pursuant to the Corporations Act 2001 (Cth) ("the Act"), the primary responsibility to ensure that financial planners meet their legal obligations in the provision of financial product advice rests with an

Copyright (C) 2007 Victoria University. This document has been published as part of the Journal of Business Systems, Governance and Ethics in both online and print formats. Educational and non-profit institutions are granted a nonexclusive licence to utilise this document in whole or in part for personal or classroom use without fee, provided that correct attribution and citation are made and this copyright statement is reproduced. Any other usage is prohibited without the express permission of the
Australian Financial Services Licensee ("AFS Licensee") which employ or authorise financial planners to represent them. These Licensees are usually companies. Financial planning, like health care (Khusf 1998) is being practiced by institutions, not just by individual advisors.

Whilst transition to the new Financial Services Reform Regime was completed on 
11 March 2004, there is little focus within the legislation on the ethical obligations and decision making of the individual advisor. Most of the legal duties, such as the obligation to provide financial product advice in a fair, honest and reasonable manner or to manage, control or avoid conflict of interest rest with the AFS Licensee (ASIC 2004a; ASIC 2004c). Further, the new Act does not cover all areas of advice that may be given by a financial planner such as estate planning and strategic advice.

There is also a current public perception that despite the new regulatory regime, financial planners are unethical and incompetent (ASIC 2003), with their professional role being shaped by scams and scandals (Vessenes 1997; Bruining 2004; Brown 2003), and a system of rewards that are perceived as being associated with self interest (ASIC 2004b; Wolthuizen 2003).

It is argued that for financial planning to be regarded as a profession, it requires more then the new regulatory structure provided by the Act. It also requires a focus on the individual advisor as a professional, a strong ethical context, an altruistic motive rather then individual self interest and a high degree of self control of behaviour usually articulated in a Code of Ethics and other ethical frameworks (Barber 1988; Wagner 2004; Miller 2002). Whilst some financial planners are members of a professional association such as the Financial Planning Association of Australia or CPA Australia, and are thus bound by a Code of Ethics, there is no compulsion to be a member. It is also argued there may be gaps in the existing frameworks such as a focus on training or professional development in ethics, and the existence of formal ethical frameworks in financial planning firms.

The issues identified in the introduction provide a catalyst for our research. Our study will be one of the first of its type conducted in Australia on financial planners. It will identify the levels of ethical reasoning and the cognitive frameworks used by financial planners when making ethical decisions in the provision of financial advice, as well as the current ethical climate and culture within financial planning firms. It will investigate the factors that may be influencing financial planners in their ethical decision making, and explore gaps in the industry's existing ethical and regulatory framework.

\section{Financial Planning: the Focus on Ethical Decision Making}

Financial planners deal with a range of ethical dilemmas in their daily practice, which often arise in circumstances where there are multiple stakeholders, interests and values in conflict and where the law may be uncertain. The relationships financial planners have with their clients and the ethical framework that underpins them is pivotal to the ability of the financial planner to provide a professional and effective service and resolve these dilemmas effectively. The study aims to refocus attention on the value that professional judgment and ethical decision making can bring to the resolution of issues facing financial planners in the provision of advice to clients.

The factors that may influence that judgment also warrant greater attention. We believe the ethical climate and culture of the AFS Licensee have a significant role to play in positively influencing the ethical conduct of employees and advisers and with suitable role models, should also assist the licensee to embed a culture of compliance. The ability to influence this ethical context may have a bearing on the AFS Licensee's ability to meet its obligations, to provide services in an efficient, fair and honest manner, its reputation within the marketplace and the quality of the advice that will be given to clients. The study will endeavour to prove these links exist.

This is a relatively under-researched area. Only financial planners in the United States seem to have been the subject of a study relating to levels of ethical reasoning (Bigel 1998).

This study will replicate parts of Bigel's study on levels of ethical reasoning of financial planners within an Australian context and investigate and identify factors influencing the ethical reasoning of financial planners, in addition to analysing the impact of those factors on the ability of financial planners to meet their professional and ethical obligations. 


\section{The Key Objectives}

The study's specific aims are to:

1. Identify the level of ethical reasoning of financial planners and the cognitive frameworks used to make ethical decisions in the provision of financial planning advice;

2. Identify factors influencing the ethical reasoning of financial planners and analyse the impact these factors are having on the ability of financial planners to meet their professional and ethical obligations to clients;

3. Investigate the dynamic between the individual financial planner and the organisation for whom they work, including the perceptions financial planners have of the ethical climate and culture of the organisation and whether these may be factors influencing their ability to meet their professional and ethical obligations;

4. Compare these perceptions to those of the compliance officer who is responsible for supervising the advice given by a financial planner, and

5. Identify any gaps in existing ethical frameworks within the financial planning industry and develop a model ethical framework for financial planning firms which may include a model Code of Ethics, a model of practical moral reasoning and a framework for ethical decision making.

This study will provide direction on how to align the ethical reasoning and professional obligations of an individual practitioner, with the organisation for whom they work and the ethical expectations of their stakeholder groups. It will also provide a foundation from which to develop a model ethical framework for financial planning firms that incorporates the ethical expectations of stakeholder groups and links the commercial imperatives of the financial services industry, the legal obligations of an Australian Financial Services Licensee, and the professional obligations of the financial planner. This may include a model Code of Ethics, a model of practical ethical reasoning and a framework for ethical decision making

Our key objective is to contribute to the debate on how Australian financial planners can fulfil their obligations as an emerging profession within the multi-national and commercial environment of an increasingly globalised financial services industry in the $21^{\text {st }}$ century.

\section{The Theoretical Context}

Ethics is fundamentally interested in character. Francis (1994) has described it as a highly explicit form of behaviour designed to produce particular ends and actions in accordance with particular value systems. He describes the term "morals" on the other hand as standards held by the community, often in a form not explicitly articulated. Ethical principles can stem from consideration of principles at two levels: high level principles such as equitability, dignity and honesty and second level principles such as the avoidance of conflicts of interest when making commercial decisions (Francis 2000).

This study will be concerned with a financial planner's level of ethical reasoning, the values and tools they use in their ethical reasoning process in their role as professional advisers, as well as the decisions and behaviours that result from them (Weiss 2003). It will not be a study concerning religious beliefs and personal morality per se. The term "ethical behaviour" will be defined as not just ethical reasoning, but also the relationship between this reasoning and conduct (de Casterle et al. 1998, Rest \& Narvaez 1994).

The concept of a profession by definition implies infinite levels of ethical complexity and ambiguity in decision making (Francis 1994). This demands a strong ethical context and a high degree of self control of behaviour, usually articulated in a Code of Ethics (Barber 1988). Whilst acknowledging that there is no absolute common morality that can be identified in such a Code (Seedhouse 1994), it should refer to 
moral principles and ideals of the good, it should reinforce desirable behaviour, the character (habits) and affective attitudes that condition and motivate that behaviour (Miller 2002).

Professional ethics and legal principles seldom exist in isolation (Winston et al. 1998). Aspirational ethical standards for financial planners should sit above the legal obligations of the Act to ensure this level of decision making can take place. Such standards and the minimum legal obligations in the Act can be complementary aspects of regulatory control (Coady and Sampford 1993).

Whilst there have been numerous studies of the ethical reasoning of other professionals such as accountants (Armstrong 1984; Arnold and Ponemon 1991; Porco 2003), medical students (Munro et al. 2003), journalists (Westbrook 1994) and nurses (de Casterle et al. 1998; Thissen 2003) only financial planners in the United States seem to have been the subject of a study similar to the one proposed (Bigel 1998).

Bigel's study of the level of ethical reasoning amongst U.S financial planners is based on Kohlberg's work (Bigel 2000). Kohlberg (1976) argued that the development of an ethical sense goes through phases that represent more significant levels of ethical reasoning. Kohlberg (1969) identified a total of six stages across three levels of ethical development: the pre-conventional, the conventional and the post-conventional, based on the premise that ethical maturity evolves and can be measured by the different ways in which people organise and structure their social and moral world and associated experiences. At stage one, ethical judgement is motivated by a desire to avoid punishment. At stage six, judgement is motivated by the individual's own conscience. Studies have shown that few individuals progress to the post-conventional level (Weber and Green 1991), with the majority of individuals motivated by either a need to avoid isolation from a group or to abide by governing laws (Kelloway et al. 1999).

Kohlberg (1976) argued there is a relationship between ethical reasoning (and judgement) and ethical behaviour. Rest's (1984) model confirms this and suggests that ethical behaviour emerges from a process of (a) recognising an ethical issue, (b) making an ethical judgement, (c) establishing an ethical intent and (d) engaging in ethical behaviour (Jones 1991, Rest \& Narvaez 1994). A high level of ethical reasoning is required to act according to high ethical standards and a person cannot follow high ethical principles if they neither understand nor believe in them (Rest 1984). The proposition that a high level of ethical reasoning among financial planners will be necessary for them to meet their professional obligations to clients is consistent with these models.

Criticism of Kohlberg's work includes arguments that cognitive development is not the only contributor to ethical development, that the work is based on western ideologies and ethnocentrics (Langford 1995), that it fails to properly address gender differences (Francis 2000) and social experience (Gilligan 1982). Researchers have therefore moved from a sole focus on individual cognitive development as a predicator of individual behaviour (Kelloway et al. 1999). This study will therefore consider individual factors (values and ethical development of the financial planner as measured by Rest's model), situational and contextual factors (the ethical climate and culture of the financial planning organisation as measured by Trevino's model). This approach recognises that ethical decision making is determined by numerous factors (Suzuki \& Knudson 1989) and recognises Preston's (1999) contention that the ethical obligations of a professional stems from the role they play or institution they serve.

There is relatively little empirical work in this area in relation to financial planners. Bigel's (1998) study focused on only two correlates to individual ethical reasoning, being compensation or payment sources and professionalisation (as defined by him by the attainment of the Certified Financial Planner ${ }^{1}$ designation which comprises specialised study, examination, and ethics for financial planners). He found that Certified Financial Planner designees scored higher on Rest's moral judgement scale then other financial planners. Fee based financial planners manifested no significantly different development scores then combination or commission based planners.

CERTIFIED FinANCIAL PlANNER TM and CFP® are marks owned by the Certified Financial Planner Board of Standards, inc. (USA) and used by the FPA under license. 
It is the dynamic between the individual planner and the organisation for which they work and the factors within that relationship which may be influencing individual ethical behaviour and reasoning, which is of additional interest to the researchers. Jackall (1998) and Pederson (1999) argue it is inevitable that corporate structures, organisational norms and payment structures will conflict with individual values and beliefs, and that this makes independent ethical thinking impossible. This may be a factor influencing the ethical behaviour and the development of high ethical reasoning in financial planners engaged or employed by large financial institutions in particular (Braithwaite 1993; Lepper 1983). It is also not a phenomenon unique to financial planning, but known to other professions such as the law (Cull 2002) and accounting (Brown 2002).

There appears to be no empirical data on the ethical climate and culture of financial planning organisations, despite significant studies in other areas such as not for profit organisations (Deshpande 1996), IT managers (Okpara 2002) and marketers (Barnett 2000). This study therefore will investigate the determinants of ethical behaviour in financial planning organisations to increase the understanding of factors that are associated with the ethical decision making of the individual advisor. It may be, for example, that any discrepancy between a financial planner's internal ethical values and their perception of management and ethical climate within the organisation, results in a moral conflict and cognitive dissonance.

This study will use the Ethical Climate Questionnaire developed by Victor and Cullen (1988) and modified by Trevino et al. (1998) to measure how financial planners view the ethical climate of the organisation for which they work. Victor and Cullen (1988) defined ethical climate as a shared perception of what behaviour is right and what behaviour the organisation expects from its members (Kelloway et al. 1999). This is based on the assumption that group members know what the climate is and can describe it in an objective way to outsiders (Weber 1993). The model suggests five climate types:

1. Caring (friendship, team interest, social responsibility);

2. Law and Code (use of ethical principles from outside the organisation);

3. Rules (use of organisation's ethical principles);

4. Instrumental (maximising self interest on an individual or organisational level);

5. Independence (use of personal ethical values in decision making).

These climates correspond to three major classes of ethical theory: egoism, utilitarianism and deontology and are consistent with Kohlberg's theory of moral development (Cullen 2001).

This research is important because an organisation's ethical climate should help to determine:

a) What employees/advisers believe constitutes ethical behaviour at work;

b) Which issues employees/advisers consider to be ethically pertinent; and

c) What criteria they use to understand, weigh and resolve issues.

The study will examine whether the ethical climate of the organisation is effectively contributing to the:

a) Types of ethical choices and conduct that the organisation wants from its employees/ advisers; and the

b) Quality and consistency of ethical decision making.

For it to be effective, the ethical climate must also be consistent with and contribute to the strategic direction and goals of the organisation. The study will measure whether this is in fact happening.

Ethical culture, defined by Trevino et al. (1990) to mean the formal and informal control systems within an organisation, will also be measured. 


\section{Methodology}

One research question relates to the current level of ethical reasoning among financial planners. Currently financial planners derive from a diverse range of educational and professional backgrounds. There is no minimum undergraduate degree entry as would be expected of a true profession. Further, only planners who either have an undergraduate degree or who hold professional designations such as Certified Financial Planner or CPA will have been exposed to formal training in ethics and professional obligations. This may influence the level of ethical reasoning currently held by financial planners. Age and gender are also two demographic variables that have been tested as factors which influence ethical reasoning. Studies have suggested in particular that the moral development and reasoning of men and women differ (Gilligan 1982, Straub 1994, Dawson 1992). Bigel's (1998) study also tested the correlation between compensation source and ethical reasoning.

Accordingly, the study will examine whether the ethical reasoning of financial planners differs according to experience, gender, age, education level and compensation source.

Research has shown that employees desire consistency between their ethical value system and the ethical climate of their organisation (Okpara 2002). Further, the ethical climate of an organisation plays a major role in addressing specific unethical behaviour (Whitehead and Novak 2003). It might be that one influence on the levels of ethical reasoning and ethical behaviour of financial planners within Australia is a weak organisational system where acceptable ethical behaviour is not clearly defined and ethical culture is not promoted. It is anticipated that the existence of formal and informal ethical frameworks within financial planning organisations will also be rare and may be an influencing factor. It may also be that differences in perception and levels of ethical reasoning between financial planners and compliance managers are influencing outcomes.

Accordingly, the study will determine whether the levels of ethical reasoning and perceptions of ethical climate will differ between financial planners and compliance managers and whether Financial Planners who exhibit low levels of ethical reasoning will be employed by organisations where systems related to ethical culture are weak and the ethical climate is perceived as rules based.

Another question to be answered by the research is whether a rules based climate (which it is expected will be perceived as the most likely climate type among financial planning organisations given the heavy regulation of the financial services industry), is sufficient to allow financial planners to meet the aspirational ethical standards expected of them or impedes their ability to achieve high levels of ethical reasoning and undertake a principled, creative and flexible approach to ethical decision making (Dal Pont 2003).

The research will also consider whether the perception of an instrumental climate within a financial services organisation is associated with a perception of higher levels of unethical behaviour among peers, given the emphasis within that climate on self interest.

The research will consist of six stages. Stage One will consist of an analysis of complaints of unethical behaviour made against financial planners to ASIC and the alternative dispute resolution scheme for financial planning complaints, the Financial Industry Complaint Service over the last two years.

The next three stages will be concerned with the development of case scenarios, derived from this analysis, that describe ethical dilemmas, a pilot survey of financial planners to assist in identifying factors they believe may be influencing the ethical decision making of financial planners and the formulation of the research questionnaire.

The first part of the questionnaire will use the scenarios developed in Stage Two and Rest's (1984) short form of the Defining Issues Test (the "DIT"). This part will measure levels of ethical reasoning and the methods adopted by financial planners in solving professional ethical dilemmas. Each scenario will be followed by groups of questions to discern how the participants' reason, act in that situation perceive the conflict and how they arrived at the perceptions held (Hansen and Morrow 2003). The 
higher the score the more the subject makes ethical judgements akin to Kohlberg's highest level of ethical reasoning.

Whilst the DIT has limitations, it has been extensively tested over time and is justified on the empirical literature. All scales have acceptable levels of reliability. The DIT is also indicative of a taxonomy of ethical development particularly as it may be used to reflect post conventional thinking and is a written test which is easily administered by mail survey.

A replicated version of Bigel's (1998) demographic questionnaire will also be used to inquire into the participant's education, employment, compensation, career experience, age and gender.

The second part of the research questionnaire will be a modified version of the instrument used by Trevino et al. (1998) in a study of 1200 alumni of U.S. private colleges. The questions will measure the organisational characteristics, ethical climate and culture of the financial planner's work place. All items will be measured using a seven point Likert scale. The subjects' perceptions of ethical climate will be based on the Ethical Climate Questionnaire developed by Victor and Cullen (1988) as modified by Trevino et al. (1998) and will measure the five theoretical climates outlined previously, being caring, law and codes, rules, instrumental and independence. This part of the instrument will also test the financial planner's perceptions of the possible factors influencing their ethical decision making, as identified by the pilot study of financial planners.

The fifth and sixth stages of the study will comprise full data collection and analysis of the research questionnaire responses and delivery of findings. It is estimated that there are currently between 15,000 and 18,000 financial planners in Australia (Spits 2003) so the study's sample group of 1,000 financial planners, drawn from the membership lists of peak professional associations representing financial planners and ASIC registers, should represent approximately $7 \%$ of the industry. The sample will be stratified by education level, compensation source, age, gender and experience. To be part of the study, subjects in this group must represent or be authorised to represent an Australian Financial Services Licensee in the provision of financial product advice to clients.

The second group will be a random sample of 100 compliance managers of financial planning organisations drawn from the ASIC register of Australian Financial Services Licensees under the Corporations Act 2001 (Cwlth). The replication of the study with this group is designed to determine whether their level of ethical reasoning and perceptions of ethical culture and ethical climate within financial planning firms, differ from those held by financial planners.

\section{Conducting the Study}

The pilot studies are expected to be conducted in early 2007. Data collection for the main study is due to begin in April/May 2007 and final findings released in early 2008.

\section{Conclusion}

Our study will be one of the first of its type conducted in Australia on financial planners. It will identify the levels of ethical reasoning and the cognitive frameworks used by financial planners when making ethical decisions in the provision of financial advice, as well as the current ethical climate and culture within financial planning firms. It will also investigate the factors that may be influencing financial planners in their ethical decision making, and explore gaps in the industry's existing ethical and regulatory framework.

This study will refocus attention on the impact ethical decision making and conduct can have on the quality of financial advice provided by financial planning practitioners.

The study will provide direction on: 
- How to align the ethical reasoning and professional obligations of an individual practitioner, with the organisation for whom they work and the ethical expectations of their stakeholder groups.

- The development of a model ethical framework for financial planning firms that incorporates the ethical expectations of stakeholder groups and links the commercial imperatives of the financial services industry, the legal obligations of an Australian Financial Services Licensee, and the professional obligations of the financial planner.

This study also will contribute to the current debate on how Australian financial planners can fulfil their obligations as an emerging profession within the multi-national and commercial environment of an increasingly globalised financial services industry in the $21^{\text {st }}$ century.

\section{References}

Armstrong, M. B. 1984, "Internalisation of the professional ethic by Certified Public Accountants: A multi dimensional scaling approach", Unpublished Doctoral Dissertation, University of Southern California.

Arnold, D. \& Ponemon, L. 1991, "Internal auditors' perceptions of whistleblowing and the influence of moral reasoning", Auditing: A Journal of Practice and Theory, Fall 1-115.

Australian Securities and Investment Commission 2003, Survey on the Quality of Financial Planning Advice - ASIC Research Report, February, ASIC, Sydney.

Australian Securities \& Investment Commission 2004, Preferential Remuneration Project - An ASIC Report, April, ASIC, Sydney.

Australian Securities \& Investment Commission 2004, Disclosure of Soft Dollar Benefits - An ASIC Research Report, June, ASIC, Sydney.

Australian Securities \& Investment Commission 2004, The Management of Conflicts of Interest - An ASIC Research Report, February, ASIC, Sydney.

Barber, B. 1988, "Professions and emerging professions", in Callahan, J.C. (eds.) Ethical Issues in Professional Life, Oxford University Press, New York, pp.35-38.

Barnett, T. 2000, "The moderating effect of individual perceptions of ethical work climate on ethical judgements and behavioural intent," Journal of Business Ethics, October, part 2, vol. 27, issue 4, p.351.

Bigel, K. S. 1998, "The correlations of professionalization and compensation sources with the ethical development of personal investment planners", Financial Services Review, vol. 7, pp.223-236.

Bigel, K. S. 2000, "The ethical orientation of financial planners who are engaged in investment activities: A comparison of United States practitioners based on professionalization and compensation sources", Journal of Business Ethics, vol. 28, issue 4, pp. 323-337.

Braithwaite, J. 1993, "Responsive business regulatory institutions", in Coady, C.A.J. \& Sampford, C.J.G. 1993, Business Ethics and the Law, The Federation Press, Sydney.

Brown, R. M. C. 2003, “Salesmen can't be planners”, The Australian Newspaper, 11 June, Wealth p.2.

Brown, R. M. C. 2002, “Have the professions lost the plot?" Living Ethics, Newsletter of St. James Ethics Centre, Winter, issue 48, pp.6-7.

Bruining, N. 2004, "Planners found to be liable over tax scheme loss", The West Australian Newspaper, Business News, 19 July, p.30.

Coady, C.A.J \& Sampford, C.J.G. 1993 Business Ethics and the Law, The Federation Press, Sydney.

Cull, K. 2002, "Presidents message: The role of the profession", N.S.W. Law Society Journal, February, p.3.

Cullen, J. B., Victor, B., \& Stephens, C. 2001, “An ethical weather report: Assessing the organisation's ethical climate." Organizational Dynamics, Autumn, vol. 18, issue 2, p.p50-63.

Dal Pont, G. 2003, "Ethical Issues Confronting Lawyers - What Should I Do When?" Paper presented to the 13th Commonwealth Law Conference, Melbourne, 13-17 April. 
Dawson, L. M. 1992, "Will feminization change the ethics of the sales profession?" Journal of Personal Selling and Sales Management, Winter, vol.12, issue 1, p.21.

de Casterle, B. D., Rulens, A. \& Gastrams, C. 1998, "An adjusted version of Kohlberg's moral theory; Discussion of its validity for researching in Nursing Ethics", Journal of Advanced Nursing, April, vol. 27, issue 4, pp.829-836.

Deshpande, S. P. 1996, "The impact of ethical climate types on facets of job satisfaction," Journal of Business Ethics, vol.15, p. 655.

Financial Planning Association of Australia Pty. Ltd. 1997, Code of Ethics and Rules of Professional Conduct, F.P.A., Melbourne.

Francis, R. D. 1994, Business Ethics in Australia- A Practical Guide, Centre for Professional Development, the Law Book Company Limited, Kew, Victoria.

Francis, R. D. 2000, Ethics and Corporate Governance: An Australian Handbook, University of NSW Press Ltd., Sydney.

Gallop, S. 2003, “Awareness dawning", Hong Kong Financial Planner, Autumn, issue 3, p.12, Institute of Financial Planners, Hong Kong.

Gilligan, C. 1982, In a Different Voice, Harvard University Press, Cambridge, Massachusetts.

Hansen, M. \& Morrow, J.L. Jnr. 2003 "Trust and the decision to outsource: Affective responses and cognitive processes," International Food and Agribusiness Management Review, vol. 6, issue 3, International Food and Agribusiness Management Association.

Jackall, R. 1988, Moral Mazes, Oxford University Press, New York.

Jones, T. M. 1991, "Ethical decision making by individuals in organizations: An issues contingent model," Academy of Management Review, vol.16, pp.366-395.

Kelloway, E. K., Barling, J., Harvey, S., Adams-Roy, J. E. 1999, "Ethical Decision Making in DND: The development of a measuring instrument", Phase 1 Report, Defence Ethics Program, National Defence Headquarters, Ottowa, Canada.

Khushf, G. 1998, "A radical rupture in the paradigm of modern medicine: Conflicts of interest, fiduciary obligations \& the scientific ideal", Journal of Medicine \& Philosophy, February, vol. 23, issue 1, pp.98-122.

Kohlberg, L. 1969, "Stage and sequence: The cognitive developmental approach to socialization", in D Goslin, (ed.) The Handbook of Socialisation Theory \& Research, Rand McNally, Skokie, Illinois.

Kohlberg, L. 1976, "Moral stages and moralization: the cognitive developmental approach", in Lickona, T. (eds.) Moral Development and Behaviour Theory: Research and Social Issues, Holt Rinehart and Winston, New York.

Langford, P. E. 1995, Approaches to the Development of Moral Reasoning, Lawrence Erlbaum, Hove, United Kingdom.

Lepper, M. R. 1983, "Social control processes, Attributions of motivation and the internalisation of social values", in Higgins, E.T., Ruble, D.N. \& Hartup, D.W. (eds.), Social Cognition and Social Development: A Sociocultural Perspective, Cambridge University Press, New York.

Matteson, J. T. \& Donovan, M. Z. 2002, "Ethics and the Architect", Architectural Record, October, vol. 190, issue 10, p.96.

Miller, S. 2002, Model Code of Ethics Principles, paper prepared for the Professional Standards Council, June, P.S.C., Sydney.

Munro, D., Bore, M., \& Powis, D. 2003, "Personality factors in professional ethical behaviour: Studies of empathy and narcissism", Australian Journal of Psychology, Supplement, vol. 55, p.54.

Okpara, J. O. 2002 "The influence of ethical climate types on job satisfaction of IT managers; Implications for management practice and development in a developing economy." paper presented to the Academy of Business and Administrative Services Seventh International Conference, July 68, San Jose, Costa Rica.

Pederson, R. P. 1999, “Learning the hard way: That ethical behaviour can't be learned”, Community College Week, 4 May, vol. 11, issue 18, pp.12-14.

Peel, K. 2004, “P.R. problems: Why advice has failed to sell”, IFA Magazine, July 19-25, p.31. 
Porco, B. M. 2003, "Factors affecting the cognitive moral development of undergraduate accounting students: Ethical education, internships, volunteerism, and Beta Alpha Psi", PhD Thesis, Fordham University.

Powell, J. L. 2003, "Fiduciary Duties in the New Millennium: Quo Vadis", paper presented to the $13^{\text {th }}$ Commonwealth Law Conference, Melbourne, 13-17 April.

Preston, N. 1996, Understanding Ethics. The Federation Press, Sydney.

Rest, J. R. 1984, "The major components of morality", in Kurtines, W. \& Gewirtz, J. (eds.) Morality, Moral Behaviour and Moral Development, Wiley, New York.

Rest, J. R. \& Narvaez, D. (eds.) 1994, Moral Development in the Professions: Psychology and Applied Ethics, Erlbaum, Hillsdale, New Jersey.

Seedhouse, D. 1994, "Commitment to health: A shared bond between the professions", Journal of International Professional Care, August, vol.16, issue 3, p.249

Smith, J. 2003, "Current FSR issues for financial planners", Financial Services Newsletter, July, vol.2, no. 2, p. 19 .

Straub, M. 1994, "An analysis of factors affecting cognitive moral development of auditors and auditing students", Journal of Accounting Education, Spring, pp.1-24.

Suzuki, D. \& Knudson, P. 1989, Genethics, Allen and Unwin, Sydney.

Thissen, M. 2003, "Nursing Education and the Ethics of Care", MA Thesis, Concordia University, Canada.

Trevino, L. K., Butterfield, K. D. \& McCabe, D. 1998, "The ethical context in organisations: Influence on employee attitudes and behaviour," Business Ethics Quarterly, vol.8, issue 3, pp. 447 -476.

Trevino, L. K. \& Youngblood, S. A. 1990, "Bad apples in bad barrels: A causal analysis of ethical decision making behaviours," Journal of Applied Psychology, vol.75, pp. 378 -385.

Vessenes, K. 1997, “Avoiding law suits based on conflicts of interest", Journal of Financial Planning, vol. 10 , issue 6, p.22.

Victor, B. \& Cullen, J. B. 1988, "The organisational bases of ethical work climates," Administrative Science Quarterly, vol. 33, pp.101-125.

Wagner, R. B. 2004, "To think ...like a CFP”, Journal of Financial Planning, February, vol. 17, issue 2, pp.64-70.

Walker, L. J. 2003, “A not so subtle threat to professional freedom”, Journal of Financial Planning, October, vol. 16, issue 10, p.22.

Waring, T. 2003, "Do we need to worry about ethics in practice: What can really go wrong?" Australian Journal of Psychology, Supplement, vol. 55, p.111.

Weber, J. 1993, "Institutionalising ethics into business organisations: A model and research agenda," Business Ethics Quarterly, vol.3, issue 4, p. 419.

Weber, J. \& Green, S. 1991, "Principled moral reasoning: Is it a viable approach to promote ethical integrity?" Journal of Business Ethics, vol. 10, pp.325 - 353.

Weekes, P. \& Hoyle, S. 2004, "Super start out of the blocks...or not", The Age Newspaper, June 26, Business 5.

Weiss, J. A. 2003, Business Ethics: A Stakeholder and Issues Management Approach, ( ${ }^{\text {rd }}$ ed.) Thomson South Western, Canada.

Westbrook, T. 1994, "Tracking the moral development of journalists: A look at them and their work." in Rest, J. R. \& Narvaez, D. (eds.) Moral Development in the Professions: Psychology and Applied Ethics, Erlbaum, Hillsdale, New Jersey.

Whitehead, A. W. \& Novak, K.F. 2003, "A model for assessing the ethical environment in academic dentistry." Journal of Dental Education, October, pp. 1113-1121.

Wilson, W. 2004, "Soft dollars will help soft landing", Money Management, 26 February, vol. 18, issue 6, p.14.

Winston, R, B. \& Saunders, S.A., 1998, "Professional ethics in a risky world", New Directions for Student Services, no.82, Summer, Jossey-Bass, San Francisco.

Wolthuizen, C. 2003, "Professionalising the planners: A first step towards quality financial advice" Living Ethics, Newsletter of St. James Ethics Centre, issue 52, Winter, p.4. 